International Journal of Life Sciences
Available online at http://sciencescholar.us/journal/index.php/ijls
Vol. 3 No. 2, August 2019, pages: $24 \sim 32$
e-ISSN: 2550-6986, p-ISSN: 2550-6994
https://doi.org/10.29332/ijls.v3n2.299

\title{
Environmental Impacts Produced on Earthquake in Province of Manabí
}

\author{
(1) crosshate

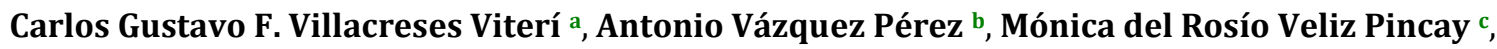 \\ Yadira del Pilar Chavez Loor ${ }^{d}$
}

Article history: Received 18 December 2018, Accepted: 30 April 2019, Published: 10 July 2019

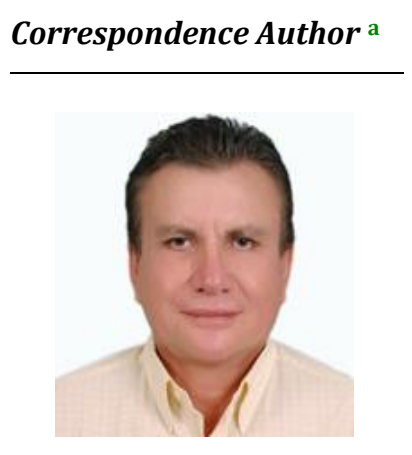

Keywords

earthquakes; environmental risks; functional value; social value; soils;

\begin{abstract}
The province of Manabí is subject to different risks, one of them is seismic. When this phenomenon occurs, they endanger all elements of society; but not only that, because the consequences of these reach further and can compromise the environmental situation of a locality when they are able to produce changes in the orography of the land modifying the landscape. Many buildings collapse and others are affected, transforming the environment in an important way. The research aims to show some environmental risks that occurred when this type of natural phenomenon occurs, for which a bibliographic review was used as a methodology, appealing to the experiences derived from the effects of the earthquake in the city of Portoviejo on April 16 of 2016, where it was possible to see abandoned areas that previously had a high functional and social value, soils have acquired other types of values; but also where different environmental impacts and changes of landscape affected by natural phenomenon are observed.
\end{abstract}

e-ISSN: 2550-6986, p-ISSN: 2550-6994@C Copyright 2019. The Author. SS Journals Published by Universidad Técnica de Manabí. This is an open-access article under the CC BY-SA 4.0 license (https://creativecommons.org/licenses/by-sa/4.0/) All rights reserved.

\section{Contents}

Abstract

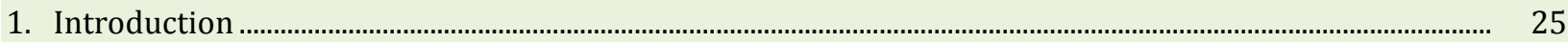

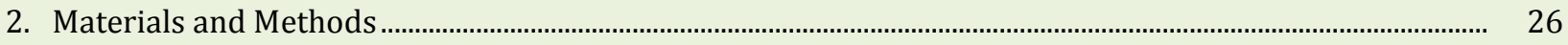

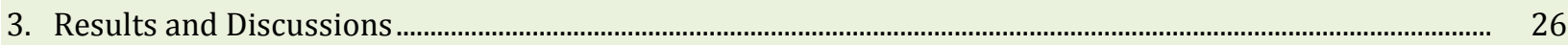

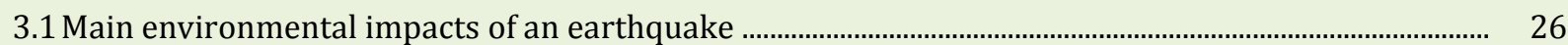

3.2 Impacts to the ground in the earthquake in Manabí ..................................................................................

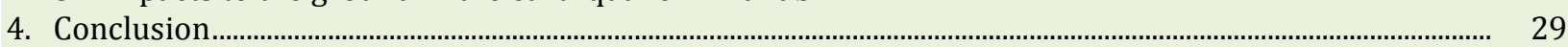

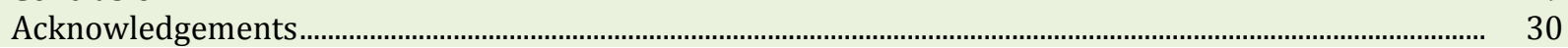

a Universidad Técnica de Manabí, Portoviejo, Ecuador

b Universidad Técnica de Manabí, Portoviejo, Ecuador

c Universidad Técnica de Manabí, Portoviejo, Ecuador

d Universidad Técnica de Manabí, Portoviejo, Ecuador 


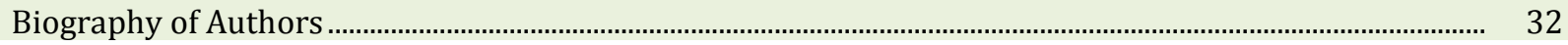

\section{Introduction}

Earthquakes mostly cause environmental impacts, from the moment the phenomenon occurs, until the anthropic action of the human helping to rebuild what was destroyed, but the first impacts are recorded in the landscape. The behavior of these phenomena is different according to the type of area where they occur. In populated areas, the effects of spills and damaged pipes (gas, water, sewage, and garbage) have noticed as time goes by. Near the epicenter of the event, it is advisable not to drink the water from the pipes as it may be contaminated.

According to studies carried out by Perez (2017), earthquakes have a high environmental impact index, not only in populated places but also in nature: the changes at the landscape level are the most obvious, then come to the aftermath on earth. The biodiversity that abounds in one sector will also have affected.

The most traumatic has related to the loss of human lives, which has a differentiated behavior from one earthquake to another, influencing the level of preparedness of citizenship to face this type of calamity (Negrete, 2018).

According to the research carried out by Calvo (1984), risk theory, in terms of geography, deals with the difficulty that human beings present when subjected to a natural environment that can bring difficulties such as dangers and threats, which could affect even the survival of the same, before the occurrence of a natural phenomenon. So that the actions of the human being as a species within an ecosystem so that its relationship with the environment is optimal and help to maintain and improve. Its quality of life is necessary to develop various forms of adaptation within a territory; in a that allows you to optimize and obtain all the necessary resources that help you to satisfy your needs and discard other aspects that may be harmful (García-Tornel, 1984), achieving the possibility of having the minimum conditions of sustainability before any type of risk.

The degradation of the environment, which has incorporated certain economic processes, is another factor that is present in the face of different catastrophes such as deforestation, rural exodus, plowing and uncontrolled expansion of the areas under cultivation, many of them with an impact on erosion. In the province of Manabí, several factors have observed after the earthquake that occurred on April 16, 2016, in different places.

One of the aspects that have been valued in terms of having resilient territories in the face of the occurrence of environmental impacts caused by natural disasters is territorial planning plans, participatory planning and the implementation of mitigation and adaptation measures to climate change. The intervention of multiple actors according to their roles and competencies (public sector, private sector, and civil society) guarantee that communities are safer and that from a local level vulnerability to future risks can be reduced (González, 2017).

Currently, several techniques of adaptive management of water resources have applied worldwide as basic elements in case of seismic risks. One of these techniques is the planning of scenarios, with approaches based on learning, flexible, and low-risk solutions. Which can contribute to adaptation to uncertain hydrological changes (IPCC, 2014)? The strategies include the adoption of integrated management of local resources the increase of supply. The reduction of the mismatch between supply and demand of water and other perishable products, the reduction of stress factors, the reinforcement of institutional capacities and the introduction of efficient technologies that allow the supply not only of water but of other necessary components such as energy.

Based on the studies carried out, it has proposed as a methodological strategy to seek information on the impacts that have caused by the natural phenomenon in order to gain clarity in relation to the planning that has developed to reduce environmental risks in the event of an earthquake. Factories and industries that can affect the environment, as they can spill toxic material that affects the health of people, soil and air. The aim of the research is to offer an analysis related to the negative effects that an earthquake can cause to the environment and therefore to the people who are in the affected territories (Meza et al., 2017; 2018).

Viterí, C. G. F. V., Pérez, A. V., Pincay, M. del R. V., \& Loor, Y. del P. C. (2019). Environmental impacts produced on earthquake in province of Manabí. International Journal of Life Sciences, 3(2), 24-32. https://doi.org/10.29332/ijls.v3n2.299 


\section{Materials and Methods}

The province of Manabí, which was one of the most affected by the earthquake of April 16, 2016, has taken as the territory for the study, valuing that among the main economic and social activities on which the life of society depends. Can has affected in an important and representative way by the occurrence of an earthquake, among which we can mention coastal and rural tourism, agriculture, industry, trade, among others, being one of the provinces that contributes the most to tourism sector, not only for its beaches; but also for its typical dishes (González et al., 2017).

The research aims to provide an overview of the endogenous resource that exists, which allows it to be a province with resilience potential based on the confrontation of an earthquake, which highlights the broad potential of renewable energy sources. The deductive method has used to interpret the risks to which the province is subject and the impact of the occurrence of an earthquake on the environment. All this in order to establish the conclusions related to the study of the subject.

\section{Results and Discussions}

\subsection{Main environmental impacts of an earthquake}

The earthquakes produce catastrophic effects in different parts of the world, most affect biodiversity from man as a fundamental entity in the trophic chain; they affect the landscape, modify river beds, roads and with it the effects of flora and fauna, because in the case of fauna, in many cases they also change the habitat.

Figure 1 shows some of these environmental impacts caused by the occurrence of the earthquake in the province of Manabí, many of these were present in the roads, housing, building infrastructure (in buildings fundamentally).

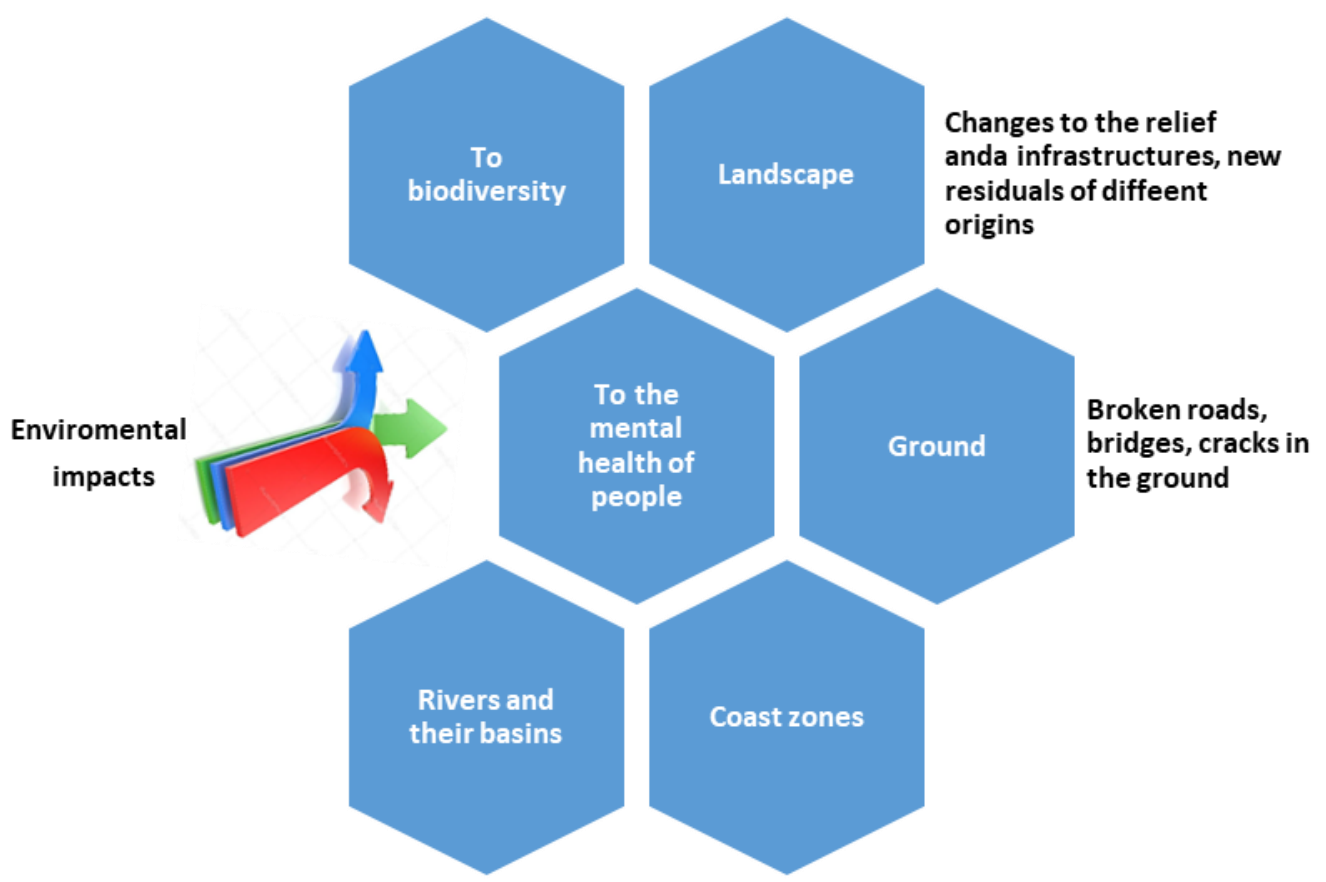

Figure 1. Some environmental impacts caused by an earthquake

Figure 2 shows photos with real impacts derived from the occurrence of an earthquake. In A the effects of liquefaction are shown in the terrain and in B other impacts in the terrain. 
A

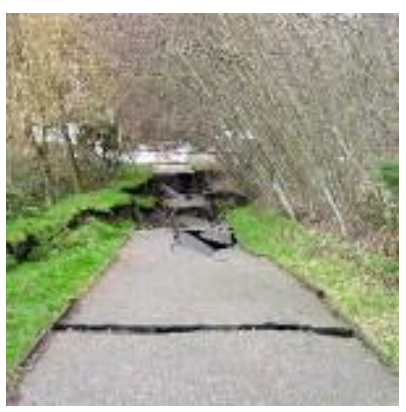

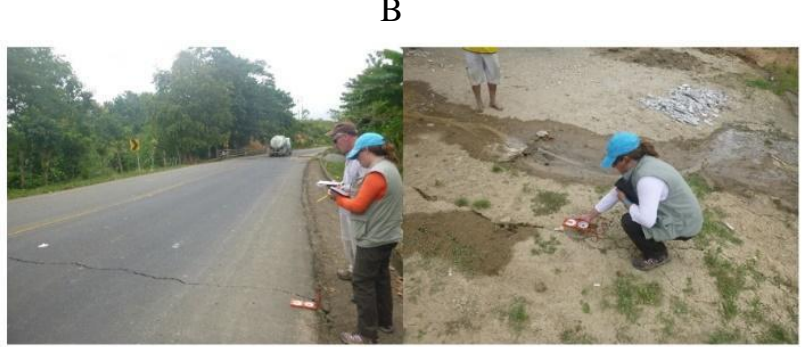

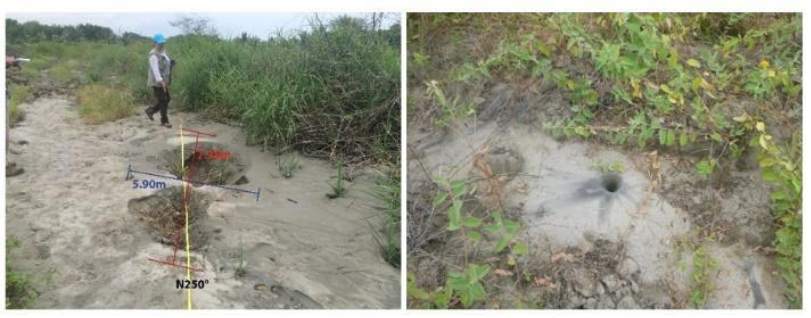

Figure 2. Environmental impacts caused by an earthquake

In figure $2(\mathrm{~A})$, the trees are observed inclined and how the ground has subsided due to its own weight. During the rehabilitation process, many trees will have to be felled, in (B) it shows cracks and sand volcanoes, liquefaction product (Geophysical Institute, 2016). You can also observe changes in relief in the environment.

In the case of earthquakes that occurred in Chile, where one of the largest earthquakes recorded in history occurred, bioethics has discussed, with conflicts and dilemmas between values and ethical principles that have raised differently from ordinary health care. According to the authors (León C, 2012), they always have a great impact on public health; they cause the distribution of health resources to be reconsidered; They question current policies on health education, prevention, and emergency management, where priorities are analyzed, broad and interdisciplinary approaches, reveal the importance of global cooperation in research and obtaining reliable data.

In many cases, the psychological depression of people that have related to the loss of a relative, property or work, occurs in people who survived natural disasters. According to studies carried out by Álvarez (2018), in the earthquake in Mexico, the increase in the population's risk of mental disorders has noted.

In Peru, which is also a country where it is very frequently affected by earthquakes, the impacts on health linked to economic damage have been investigated Barberan (2009), making the consequences of these events more human for traumatisms.

One of the most outstanding impacts in the Manabí province after the April 16 earthquake were the effects on the drinking water service. The sanitation conditions, debris and the climatic exposure of the population due to the loss of their home, generate a potential risk of diseases transmitted by water, vectors and contaminated food (WHO, 2016); in addition to people mentally affected. A study has carried out Resilience in people evacuated in the city of Portoviejo for being among the most affected (Tarazona, 2018).

\subsection{Impacts to the ground in the earthquake in Manabí}

In the case of soils in the city of Portoviejo, liquefaction phenomena occurred because special conditions for the amplification of seismic waves occurred caused mainly by the geological composition of the soil. Figure 3, shows part of the center of the city of Portoviejo, on the morning of April 17, 2016 (Bravo, 2017), where collapsed buildings are observed as a result of the high vibrations of the seismic waves.

Viterí, C. G. F. V., Pérez, A. V., Pincay, M. del R. V., \& Loor, Y. del P. C. (2019). Environmental impacts produced on earthquake in province of Manabí. International Journal of Life Sciences, 3(2), 24-32. 

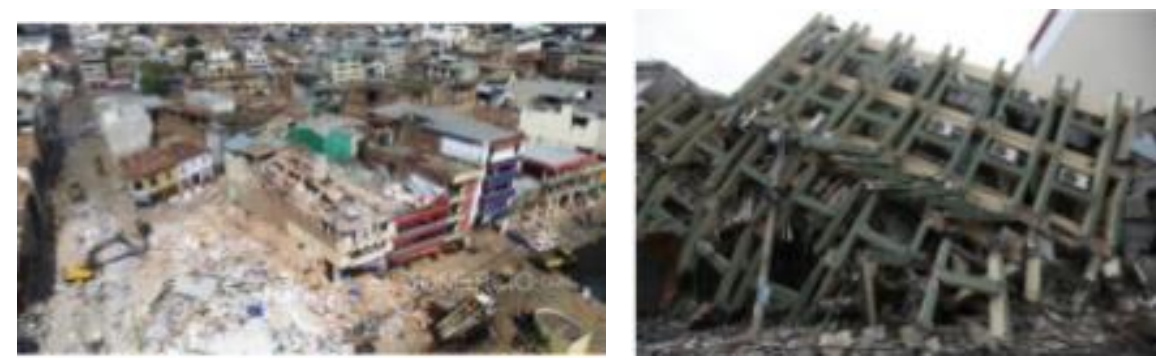

Figure 3. Collapsed buildings in the city of Portoviejo motivated by soil vibrations

As shown in the previous figure, the dramatic change in the urban landscape caused by the earthquake has shown. The air pollution caused by the dust generated in the destroyed buildings, creating a diffuse aspect in the urban climate; the appearance of a large quantity of debris that contaminates the city's environment and serves as a host to rats and other infectious insects. Figure 4 shows one of the consequences of the earthquake that caused the rarefying of the urban landscape.

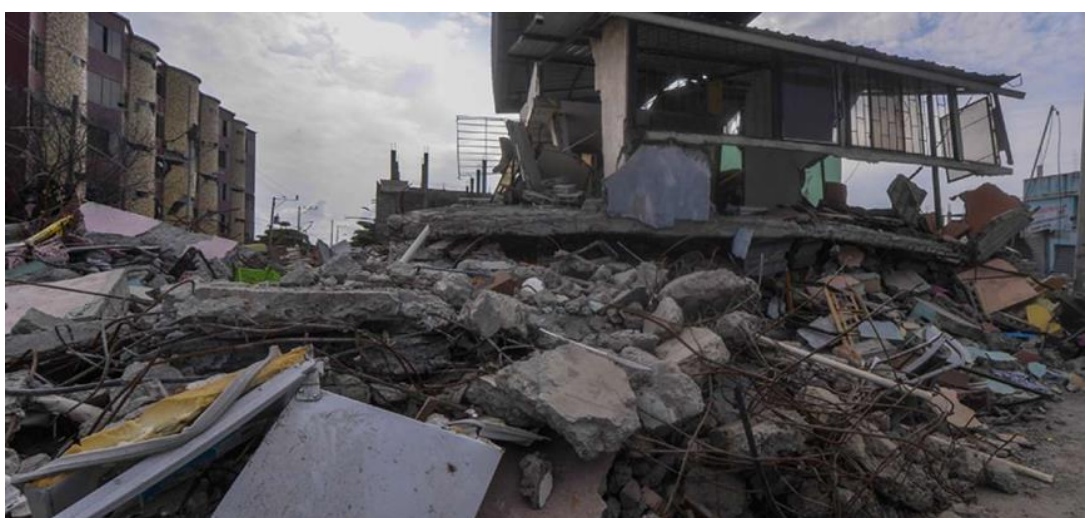

Figure 4. Lack of urban landscape caused by the occurrence of the earthquake on April 16, 2016

As far as infrastructure is concerned, about 80 kilometers of roads have affected, as well as 35,264 homes of which 13,962 houses collapsed. Fifty-one health posts, 875 schools, and 11 universities also suffered damage.

In the productive sector, 21,823 jobs were lost between formal and informal, with the same number of human beings who were unemployed. In addition, 80,000 people moved because of the earthquake of which 28,775 were sheltered in shelters and shelters; 15,000 have accommodated in shelters and the rest opted for migration, describing a very complex social panorama for the territory.

In actions of attention, 251 shelters have activated in order to relocate people in safe areas with 600 families relocated in lands built by the State or built on their own land. Specifically, in the town of Portoviejo, the resettlement of El Guabito have executed.

It is estimated that the cost for the reconstruction of the areas affected by the earthquake of April 16, 2016, amounts to 3,343 million, according to calculations made by the National Secretariat of Planning and Development (SENPLADES). In this investment for the social sector, 1,368 million will be disbursed; in infrastructure, 862 million. While in the productive sector, 1,032 million will have invested.

Some students of Political Ecology (Bravo, 2017) argue that their fundamental role as science is the interrelation of human societies with nature; besides analyzing how access, control and use of natural resources and territory occurs in a society made up of different power groups. This science emerges as a criticism of modernity, which is proven to appreciate that a significant group of modern buildings collapsed, not so with the typical homes of the Manabí environment.

Many of them resisted in an earthquake attack as shown. In figure 5, where a house has observed that has calculated between 80 and 100 years old. Which has built in two plants with endogenous materials that are 
part of the ancestral building culture of the territory, is located at the entrance to the boardwalk of the coastal city of Bahía de Caráquez and is still standing as an indelible witness of the Manabí history (Zibell, 2016).

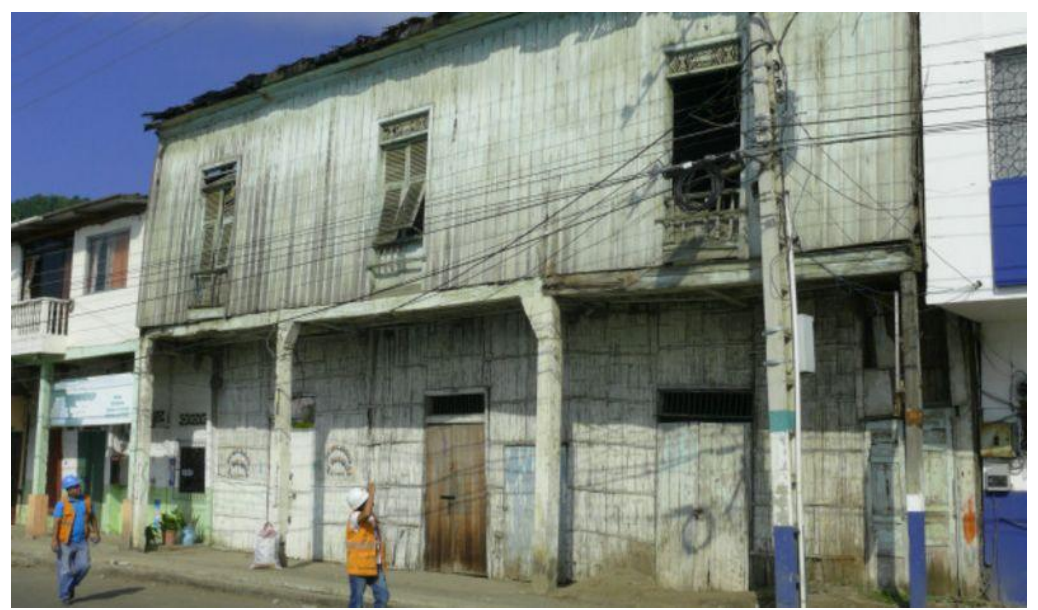

Figure 5. House built with endogenous materials

The coastal areas of the Manabí province is a territory of wide tourist coverage. These areas had a negative impact due to the fear of the occurrence of tsunamis caused by the earthquake, but also the constructions were rough, which can have seen in photos shown in figure 6.
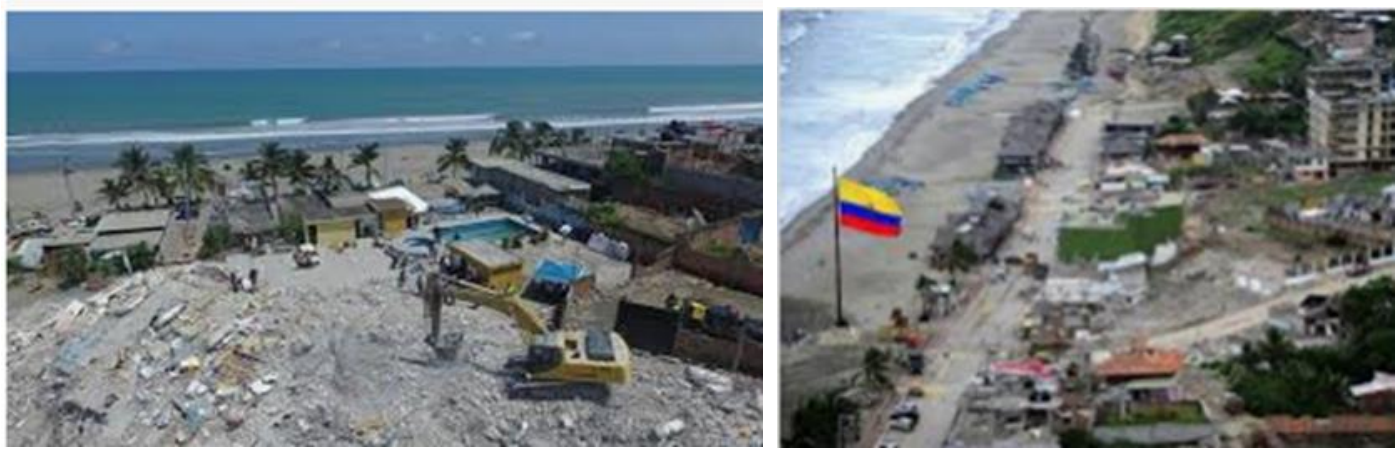

Figure 6. Photos of coastal areas by the earthquake

In the photos, you can see some of the negative impacts on a tourist landscape due to the devastation left by the earthquake. Especially collapsed buildings and others destroyed that left a scary image of debris and evictions, to which has added the massive migration of tourists and people living in those places for fear of the occurrence of a tsunami. The results shown are practical examples of the environmental impacts caused; these negative experiences can have reversed in plans and strategies that mitigate these negative effects on the environment.

\section{Conclusion}

The investigation allowed exposing an analysis related to the environmental consequences of an earthquake, especially those related to people, the constructive and economic infrastructure of society, where the extraordinary destructive potential of these phenomena could be proven, capable of testing the strengths of any society to face them and emerge strengthened from it.

Viterí, C. G. F. V., Pérez, A. V., Pincay, M. del R. V., \& Loor, Y. del P. C. (2019). Environmental impacts produced on earthquake in province of Manabí. International Journal of Life Sciences, 3(2), 24-32. https://doi.org/10.29332/ijls.v3n2.299 
The main consequences related to the negative balance of the occurrence of the earthquake of April 16, 2016, in the city of Portoviejo have shown which gives an idea ofthe seriousness of the consequences derived from the occurrence of these natural phenomena.

The results of the research demonstrate the importance of deepening the study of risk in such a way that strategies are drawn up that allows the short, medium and long term to use the endogenous resources of the province that allow creating the best conditions to face these phenomena and ensure the social resilience of the territory.

\section{Acknowledgments}

The authors would like to thank the editorial team of IJLS for their valuable time, support, and advice in completing the present paper. 
References

Adopted, I. P. C. C. (2014). Climate Change 2014 Synthesis Report.

Alvarez, DM (2018). Effect of the September 2017 earthquakes on the mental health of the population and recommended actions. Public Health of Mexico, 60.

Barberan, AC (2009). Estimation of the socio-economic impact of the earthquake in Pisco in the Peruvian health sector. [on-line], 20(2), 177-184. ISSN 1018-130X. Rev Med Hered.

Bravo, E. (2017). The April 16 earthquake in Manabí seen from the ecology of the disaster. (http://www.redalyc.org/articulo.oa?id=476151860010, Ed.) Universitas, Journal of Social and Human Sciences (26).

Calvo, F. (1984). The geography of risks. (I. 0210-0754, Ed.) Notebooks critical of human geography, IX (54).

García-Tornel, F. C. (1984). La geografía de los riesgos. Geo Crítica: cuadernos críticos de geografía humana.

Geophysical Institute. (2016). Geological survey of the effects of the April 16 earthquake in the area between MAntas and Esmeraldas. https://www.igepn.edu.ec/servicios/noticias/1332-geologico-de-los-efecto-delsismo-del-16-de-abril-en-la-zona-entre-esmeraldas- y-blanket

González, AED, Arauz, WMS, Gamez, MR, \& Alava, LAC (2017). Photovoltaic energy to face an earthquake. International Journal of Physical Sciences and Engineering, 1 (3), 1930. https://doi.org/10.21744/ijpse.v1i3.61

González, M. (2017). Erremoto of April 16, 2016: Challenges and lessons learned in the field of prevention and environmental sustainability. News and multimedia publications.

León, C. F. (2012). Bioethics in catastrophe situations such as earthquakes. Revista medica de Chile, 140(1), 108-112.

Meza, A. K. T., Chavez, S. A. R., \& Cedeno, E. A. E. (2017). Social resilience : earthquake consequences to an intense. International Research Journal of Management, IT and Social Sciences, 4(1), 24-31.

Meza, A. K. T., Freyre, J. R. A., Cevallos, M. G. O., \& Pico, M. J. M. (2018). Autonomy, Good Humor and Support Networks, Potential of Community Resilience Intervention in People Victims of the Earthquake in the Calderón Parish. International Research Journal of Management, IT and Social Sciences, 5(1), 1-8.

Negrete, MI (2018). Analysis and evaluation of the main environmental impacts post-earthquake 2016 occurred in San Vicente canton, province of Manabí, Ecuador ". (http://repositorio.puce.edu.ec/handle/22000/15065, Ed.) Repository of thesis Pontificia Universidad Católica del Ecuador.

Pérez, R. (2017). Environmental damage by earthquakes. News of the millennium, https://sipse.com/milenio/danos-ambientales-por-sismos-opinion-yucatan-269782.html

Tarazona M Katherine A., et al. (2018). Resilience before the effects of an earthquake. http://www.uct.unexpo.edu.ve/index.php/uct/article/view/845

WHO. (2016). Earthquake in Ecuador. (OP Salud, Ed.)

Zibell, M. (2016). The secret of buildings that did not fall during the earthquake in Ecuador. (https://www.bbc.com/mundo/noticias/2016/04/160422_ecuador_terremoto_problemas_construccione s_arquitectura_ab, Ed.) BBC.

Viterí, C. G. F. V., Pérez, A. V., Pincay, M. del R. V., \& Loor, Y. del P. C. (2019). Environmental impacts produced on earthquake in province of Manabí. International Journal of Life Sciences, 3(2), 24-32. https://doi.org/10.29332/ijls.v3n2.299 


\section{Biography of Authors}

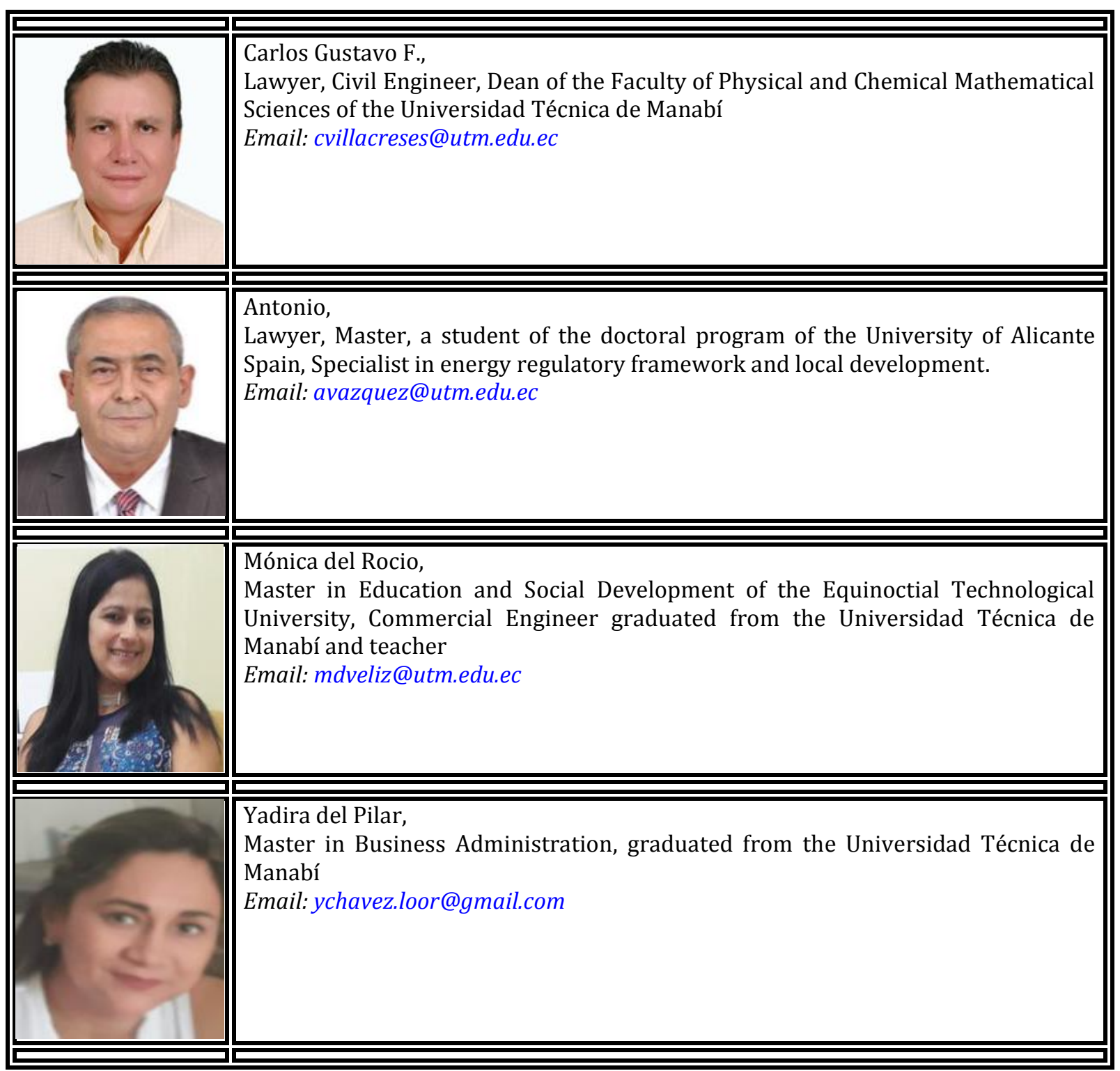

